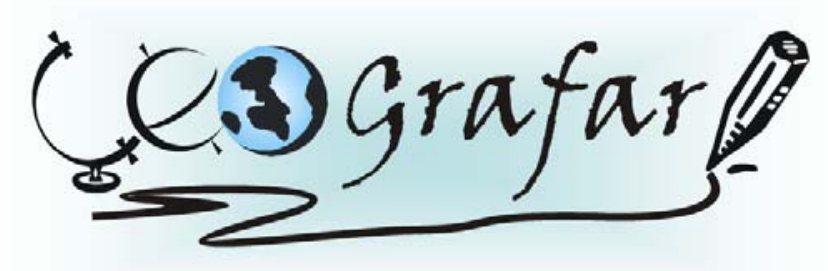

Revista Eletrônica do Programa de Pós-Graduação em Geografla - UFPR

\title{
A INFLUÊNCIA DO AQUÍFERO CARSTE EM ALMIRANTE TAMANDARÉ ${ }^{1}$
}

\author{
Maria Luiza Malucelli Araújo²
}

\section{RESUMO}

Este trabalho tem como objetivo efetuar uma análise sobre a influência do aqüífero carste no município de Almirante Tamandaré. O processo de ocupação urbana em Almirante Tamandaré está diretamente ligado à ocupação e ao crescimento do município de Curitiba, capital do estado do Paraná. Esse município foi alvo de um intenso processo de parcelamento do solo a partir da década de 1960 e é caracterizado por abrigar inúmeras ocupações que ocorreram sobre áreas com alta declividade e fundos de vale. Os principais problemas dizem respeito ao crescimento urbano, à mineração e à exploração de água, em um contexto de formação cárstica e de altas declividades, sendo que esses conflitos expõem uma contradição entre as atividades humanas, o rebatimento que projetam sobre o território e a capacidade do meio físico em dar suporte e, ao mesmo tempo, impor limitações a essas atividades. As regiões cársticas possuem uma expressiva quantidade de rochas carbonáticas, que contém um aqüífero de grande potencial, com extrema vulnerabilidade. A ocupação urbana desordenada, a exploração sem critério dos recursos naturais do carste, a mineração de calcário e a extração de águas subterrâneas formam o conjunto de fatores que causam os acidentes geológicos em terrenos cársticos.

PALAVRAS-CHAVE: aqüífero carste; ocupação urbana; Almirante Tamandaré.

\footnotetext{
${ }^{1}$ Trabalho elaborado a partir do capítulo II da dissertação intitulada "A Ocupação Urbana em Almirante Tamandaré: um desafio à sustentabilidade", defendida em 2005 junto ao Programa de Pós-Graduação em Geografia da Universidade Federal do Paraná sob orientação da professora Dra. Olga Lúcia Castreghini de Freitas Firkowski.

2 Arquiteta Urbanista, especialista em Arquitetura Bioambiental pela Pontifícia Universidade Católica do Paraná (PUCPR); especialista em Gestão Técnica do Meio Urbano pela PUCPR; mestre em Geografia pela UFPR. Arquiteta da COMEC - e-mail: maluaraujo@onda.com.br
} 


\title{
THE INFLUENCE OF AQUÍFERO CARSTE IN ADMIRANTE TAMANDARÉ
}

\begin{abstract}
This work aims at analizing the influence of the karst aquifer in the municipality of Almirante Tamandaré. The process of urban occupation in the municipality of Almirante Tamandaré is directly connected to the process of urban occupation and the growth of the municipality of Curitiba, the capital of the state of Paraná. This municipality has suffered an intense process of land development since 1950, and it is characterized by by several legal and illegal settlements on environmentally fragile areas. The main problems are related to urban growth, mining and the wather exploitation, in a context of karstic formation and high declivity rates, considering that these conflicts expose a contradiction between human activities, the impact they project on the territory, and the capacity of the physical environment to support and, at the same time, impose them limitations. The karstic region presents a significant amount of carbonatic rocks, which contain an aquifer of great potential and extreme vulnerability. The disorganized urban occupation, the exploitation without criterion of the karst natural resources, the limestone mining and the extration of underground water constitute the set of factors that cause geologic accidents in karstic terrains.
\end{abstract}

KEY WORDS: karst aquifer; urbain occupation; Almirante Tamandaré. 


\section{INTRODUÇÃO}

Este artigo pretende efetuar uma análise sobre a influência do aqüifero carste no espaço urbano do município de Almirante Tamandaré, contextualizado na aglomeração urbana metropolitana de Curitiba.

O processo de ocupação urbana em Almirante Tamandaré está diretamente ligado à ocupação e ao crescimento do município de Curitiba, capital do estado do Paraná.

O município de Almirante Tamandaré foi alvo de um intenso processo de parcelamento do solo a partir da década de 1950 e é caracterizado por abrigar inúmeras ocupações que ocorreram sobre áreas com alta declividade e fundos de vale.

Na década de 1990, devido à necessidade de abastecimento de água da população metropolitana, foram declaradas novas áreas de mananciais como de interesse e proteção especial, sendo que dentre essas áreas, está incluída uma porção significativa do município de Almirante Tamandaré, que possui em seu território mananciais superficiais e subterrâneos.

Destaca-se que outro ponto a ser considerado se refere ao fato de que a legislação do município é anterior a essas restrições, e que por esse motivo não contempla os instrumentos necessários para uma efetiva gestão do espaço.

As porções territoriais que contêm os mananciais subterrâneos, relativas ao compartimento carste, possuem um aqüifero de excelente qualidade, e se localizam ao norte da região metropolitana oficial, estando também presente em grande parte do município de Almirante Tamandaré.

$\mathrm{O}$ aqüifero subterrâneo carste possui alta fragilidade ambiental, seja pelas questões geotécnicas diante dos processos de urbanização, seja pela condição de vulnerabilidade à poluição.

O crescimento urbano, a mineração e a exploração de água são atividades que devem ser devidamente planejadas e controladas, e constituem os principais desafios no contexto urbano cárstico. Tais atividades, somadas às ocupações inadequadas do restante do território, se apresentam como um desafio à sustentabilidade urbana do município de Almirante Tamandaré.

Esses conflitos expõem uma contradição entre as atividades humanas, o rebatimento que projetam sobre o território e a capacidade do meio físico em dar suporte e, ao mesmo tempo, impor limitações a essas atividades.

\section{AQUÍFERO CARSTE}

O termo carste ${ }^{3}$ (karst) "de origem servo-croata significa campo de pedras calcárias." (OLIVEIRA, 1997, p. 3). O conceito foi empregado para designar a morfologia das formações calcárias encontradas ao norte do Adriático, na península de Istria, noroeste da lugoslávia, ao final do século XIX. (LISBOA, 1997).

${ }^{3}$ Carste: "Termo adotado no jargão técnico nacional para definir este contexto geológico." (OLIVEIRA, 1997, p. 3) 
Atualmente, o termo é utilizado para designar "as áreas calcárias ou dolomíticas que possuem uma topografia característica, oriunda da dissolução de tais rochas." (CHRISTOFOLETTI, 1980, p.153).

O principal aspecto de uma área cárstica é "a presença de uma drenagem de sentido predominantemente vertical e subterrânea (criptorréica), seguindo fendas, condutos e cavernas, com quase completa ausência de cursos d'água superficiais." (OLIVEIRA, 1997, p. 3).

A paisagem cárstica, de acordo com Oliveira (1997, p.3) "apresenta aspectos ruiniformes e esburacados, preponderantemente desenvolvidos em formações calcárias."

O sistema cárstico é constituído por três componentes principais, que se desenvolvem de maneira conjunta e interdependente: os sistemas de cavernas, aqüíferos de condutos e o relevo cárstico. (TEIXEIRA et al, 2001).

As formas ou feições da paisagem cárstica são caracterizadas pelas dolinas, uvalas, poljés, sumidouros e cavernas, conforme Lima (2004, p.6).

As dolinas, segundo Cvijic (1983 apud PILÓ, 2000, p.91) são "depressões fechadas circulares ou elípticas que se formam na superfície, em função da dissolução de rochas solúveis, normalmente em subsuperfície." Conforme este autor, "as dolinas podem atingir de poucos metros a centenas de metros de profundidade por várias centenas de metros de diâmetro." 4

As linhas de evolução de dolinas estão representadas na figura 1.

FIGURA 1 - LINHAS DE EVOLUÇÃO DAS DOLINAS

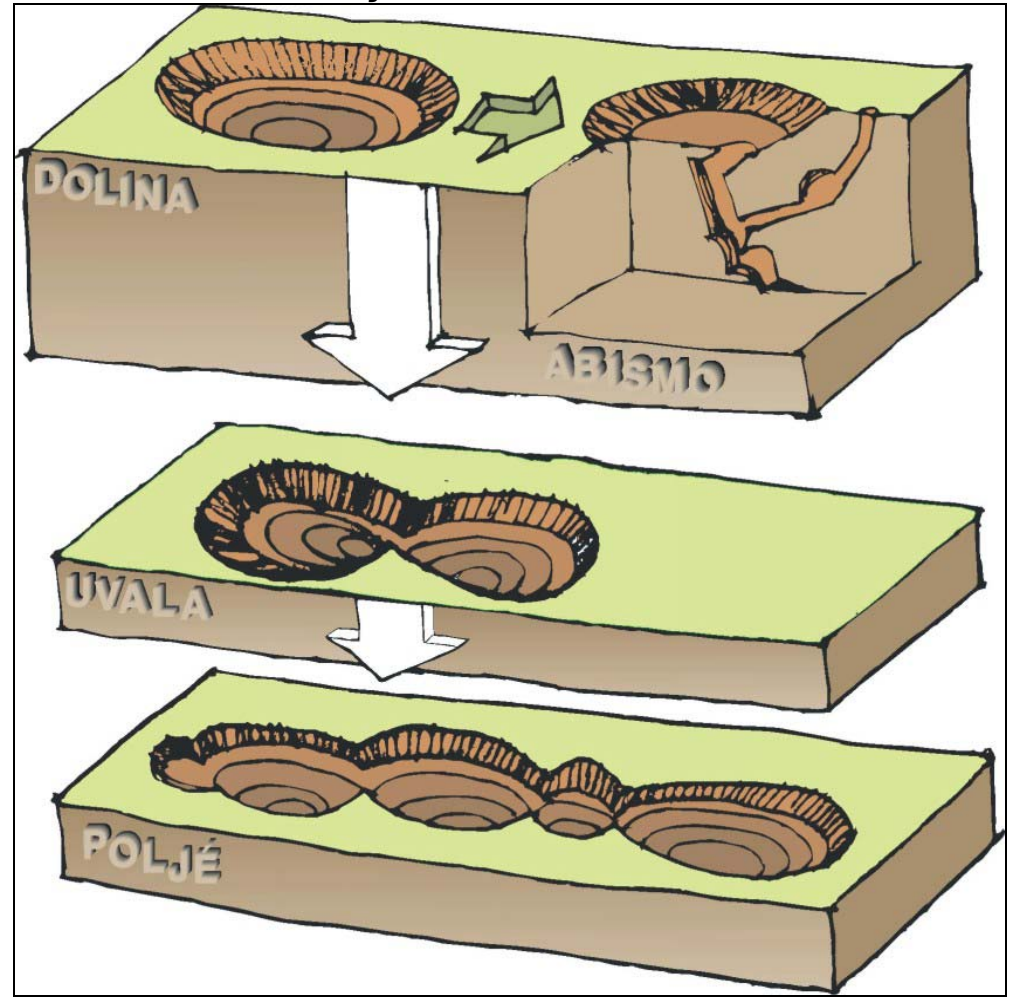

FONTE: BIGARELLA ET AL, 1994.

ADAPTAÇÃO: Maria Luiza Malucelli Araújo

${ }^{4}$ CVIJIC, J. The dolines. In: Sweeting, M. M. (Ed). 1983. Karst Geomorphology. Hutchinson Ross Publishing Company: Benchmark Papers in Geology / 59, p. 19-37. 


\section{DESENHO: Nereu Barão}

As uvalas, conforme White ${ }^{5}$ (1998 apud PILÓ, 2000, p.92), são morfologias que "podem ser interpretadas como conseqüência da dinâmica de um conjunto de depressões de dissolução que, com o tempo, vão crescendo e coalescendo".

O poljé é um termo que é utilizado para designar uma planície cárstica (CHRISTOFOLETTI, 1980, p.154) e, de acordo com definição de Piló (2000, p. 93), correspondem a "largas depressões fechadas, com comprimentos e larguras que chegam a dezenas de quilômetros de largura, com paredes abruptas, fundo plano rochoso ou, mais comumente, recoberto por argilas de descalcificação, aluviões ou depósitos lacustres." Devido à presença de aluviões, conforme esclarece Christofoletti (1980, p. 154), "os poljés são lugares preferidos para as culturas e localização dos núcleos urbanos".

Os sumidouros são áreas que podem evoluir de dolinas, que possuem uma "grande capacidade de absorção e drenagem de águas." (OLIVEIRA, 1997, p.8).

As cavernas são feições comuns às áreas cársticas e podem ser definidas como "um leito natural subterrâneo e vazio, podendo estender-se vertical e horizontalmente e apresentar um ou mais níveis. Na atualidade, podem estar ou não ocupadas por rios." (CHRISTOFOLETTI, 1980, p.155).

A circulação da água ocorre mediante circulação interna, por meio de pontos de absorção, como fissuras, dolinas etc, onde as águas superficiais desaparecem. Em pontos diferentes, próximos ou não, as águas ressurgem na superfície, através de fontes ou surgências. (CHRISTOFOLETTI, 1980). (figura 2).

O relevo do ambiente cárstico é caracterizado por partes mais arrasadas que sofreram abatimento, intercaladas por elevações constituídas por rochas menos solúveis.

Essas porções mais planas são as áreas de maior fragilidade, que, se ocupadas, poderão apresentar grande vulnerabilidade e susceptibilidade a comportamentos geotécnicos indesejáveis, com abatimentos de terreno, trazendo riscos às comunidades instaladas, bem como a necessidade de desocupação de construções.

Além disso, as áreas de carste possuem uma excelente estrutura armazenadora de água, que pode ser facilmente contaminada por ação de despejo de efluentes domésticos e industriais.

\footnotetext{
${ }^{5}$ WHITE, W. B. Geomorphology and hidrology of Karst Terrains. 1.ed. Oxford: Oxford
} University Press. 464 p. 
FIGURA 2 - ÁGUAS SUBTERRÂNEAS EM REGIÃO CÁRSTICA

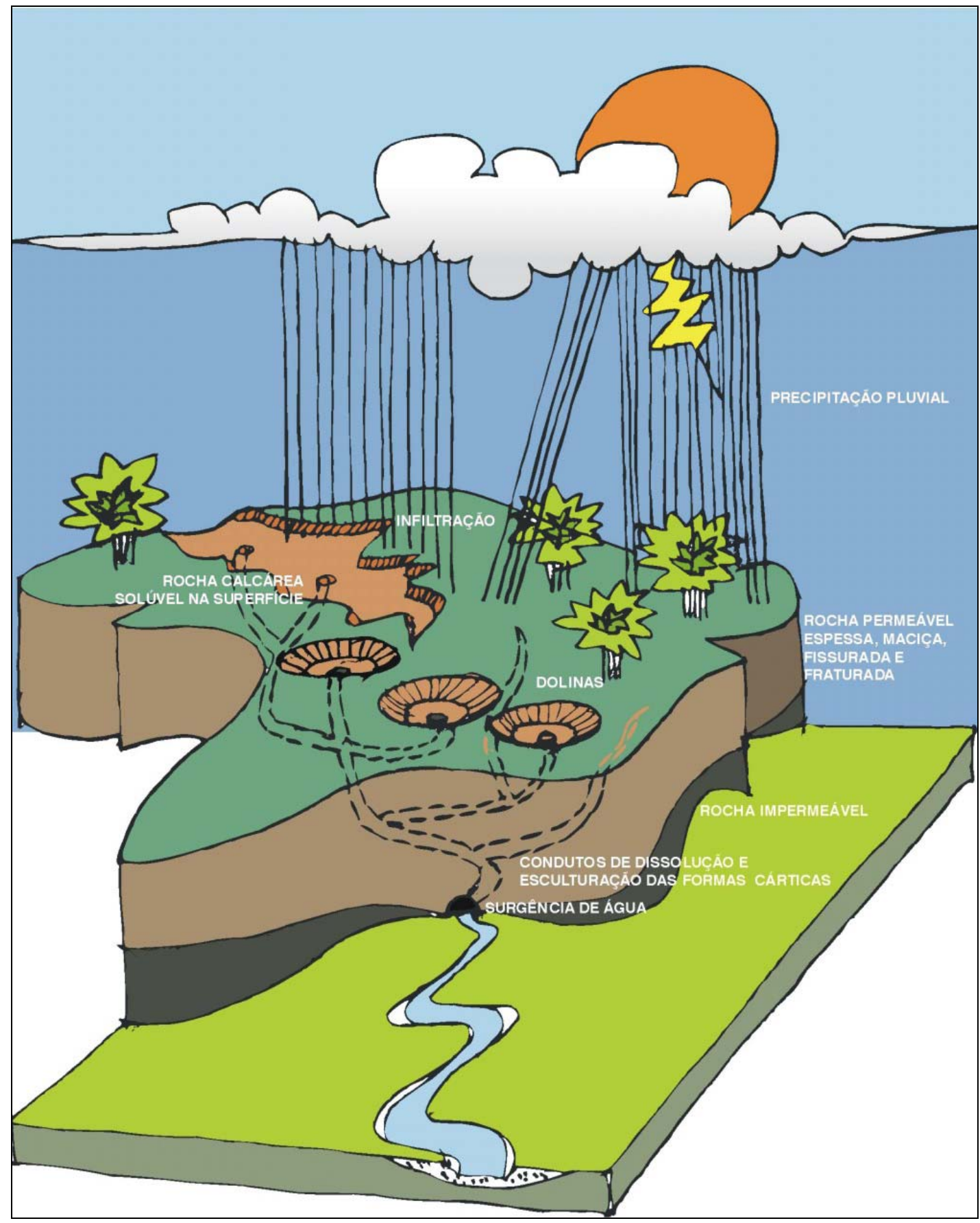

FONTE: BIGARELLA ET AL, 1994.

ADAPTAÇÃO: Maria Luiza Malucelli Araújo

DESENHO: Nereu Barão

3. A ÁREA DE ABRANGÊNCIA DO CARSTE NA REGIÃO METROPOLITANA DE CURITIBA 
A região do carste na Região Metropolitana de Curitiba foi recentemente estudada por COMEC (2002), sendo que o resultado foi o Plano de Uso e Ocupação do Solo da Região do Karst da Região Metropolitana de Curitiba.

A área de estudo contemplou parte dos municípios de Curitiba, Campo Magro, Campo Largo, Almirante Tamandaré, Itaperuçu, Rio Branco do Sul, Colombo e Bocaiúva do Sul. A porção sul da área analisada sobrepõe-se a parte da sub-bacia do Alto Iguaçu; e, a porção norte, a parte da sub-bacia do rio Ribeira. (mapa 1).

MAPA 1 - REGIÃO METROPOLITANA DE CURITIBA: ÁREA DE INTERESSE DO AQÜÍFERO CARSTE 


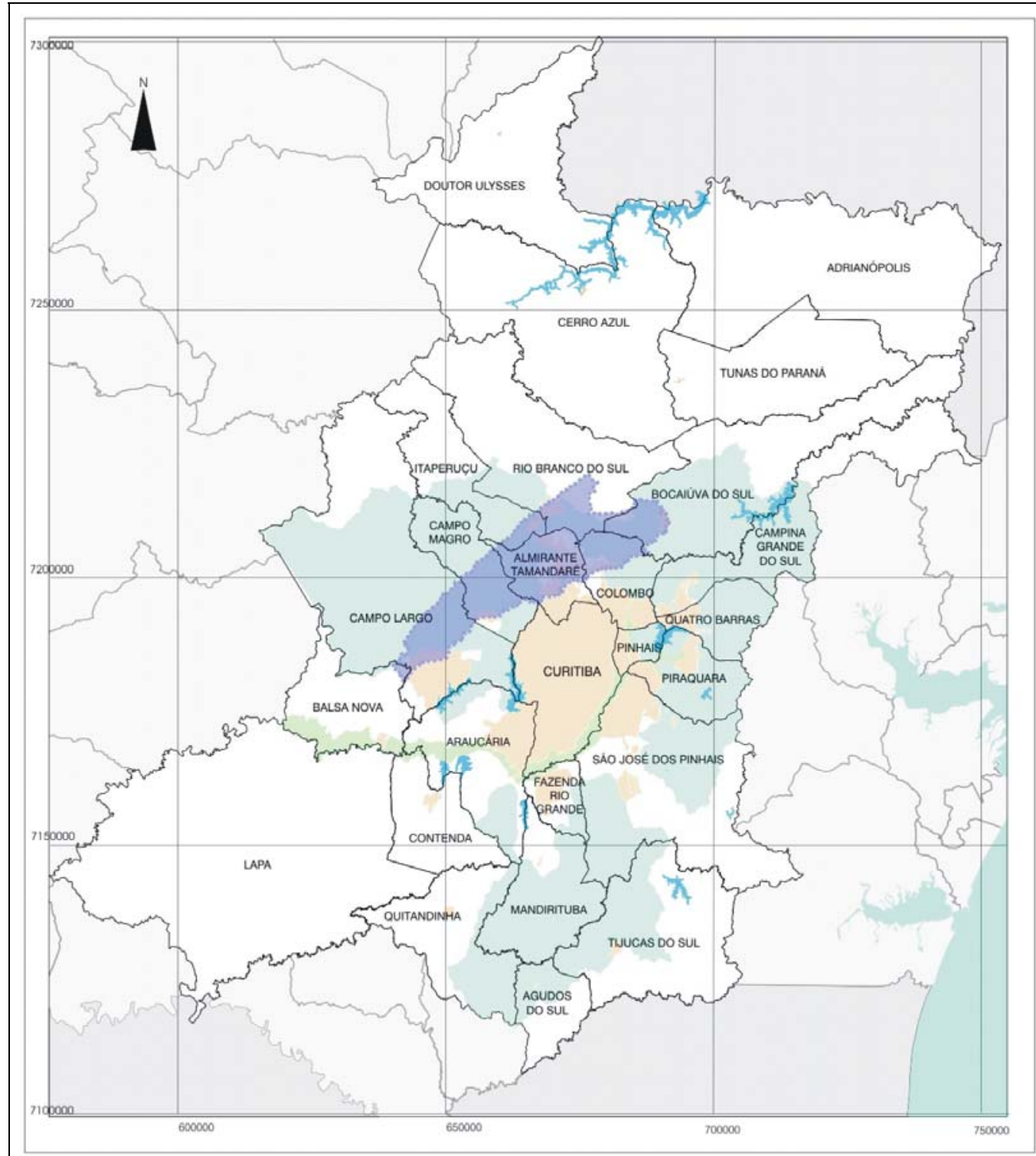

MAPA 01 - REGIÃO METROPOLITANA DE CURITIBA : Área de Interesse do Aquífero Carste

FONTE: COMEC, 2005

DESENHO : Letícia Oliveira

Escala Gráfica

$0 \mathrm{~km}$ $30 \mathrm{~km}$

\section{Legenda}

Anm Area de Interesse do Aquifero Carste

A descrição da localização do aqüifero carste, segundo COMEC (2002, p.215) é definida como: "Ao longo do limite norte da bacia do Iguaçu estende-se a faixa de rochas carbonáticas designada por karst, orientada SW-NE, origem de consideráveis mananciais subterrâneos que alimentam as nascentes de vários afluentes do rio Iguaçu e do rio Ribeira."

A região do carste possui uma expressiva quantidade de rochas carbonáticas, caracterizada em geral por terrenos planos a suavemente 
ondulados. A área de rochas carbonáticas contém um aqüífero de grande potencial, com extrema vulnerabilidade à ocupação urbana, o qual tem sido considerado como uma importante fonte para o abastecimento de água da Região Metropolitana de Curitiba.

Os metacalcários são constituídos de carbonatos de cálcio e magnésio, minerais susceptíveis à ação da água, portanto com alta capacidade de dissolução.

O armazenamento e fluxo da água do aqüífero carste é decorrente da dissolução da massa carbonática ao longo dos seus planos de fraturamento, resultante dos fenômenos tectônicos que provocaram os dobramentos e falhas da região.

Um fator de grande influência sobre as rochas é o clima, sendo considerado como ação direta a temperatura, a umidade, a precipitação e os ventos. A ação indireta do clima ocorre através da vegetação e dos solos. A manutenção da cobertura vegetal é de extrema relevância pela sua proteção de áreas com alta declividade, faixas de drenagem, dolinas etc, evitando-se processos erosivos, o fluxo de sedimentos para os corpos hídricos e a poluição do aqüífero.

O contexto morfoestrutural, conforme Lisboa e Bonacim (1995), é formado por uma compartimentação, denominada célula, onde ocorrem massas carbonáticas (metacalcários calcíticos e dolomíticos) com excelentes condições de permeabilidade, limitadas por fronteiras praticamente impermeáveis (cristas de filitos e quartzitos, entrecortados por diques de diabásio). (figura 3).

No que se refere às características quantitativas das células do carste, Lisboa (1997), define que a piezometria do aquífero carste se apresenta compartimentada segundo unidades losangulares, de acordo com 0 condicionamento litológico e morfoestrutural existente.

Segundo o autor, cada uma das unidades, denominadas de células losangulares, possui comportamento específico e independente pelo fato de serem separados por diques de diabásio.

No entanto, conforme COMEC (2002), o grau de dependência ou interligação entre células terá de ser comprovado caso a caso.

FIGURA 3 - CÉLULA DO CARSTE 


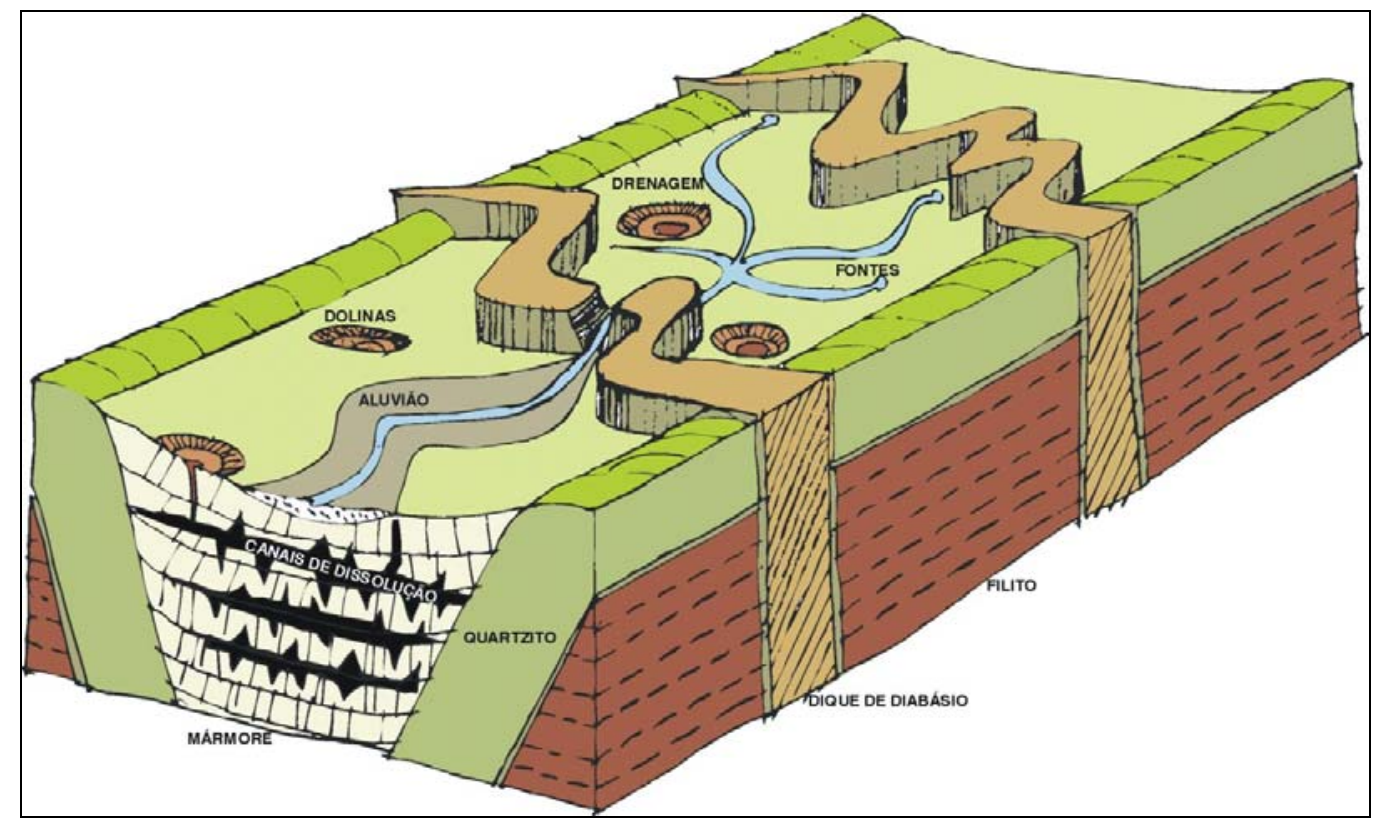

FONTE: LISBOA; BONACIM, 1995.

ADAPTAÇÃO: Maria Luiza Malucelli Araujo

DESENHO: Nereu Barão

\section{A INFLUÊNCIA DO AQÜÍFERO CARSTE EM ALMIRANTE TAMANDARÉ}

O estudo realizado por COMEC (2002) sobre o carste indicou existirem 483 células com área média de $0,319 \mathrm{~km}^{2}$, ocupando uma área total de $153,87 \mathrm{~km}^{2}$. Do total encontrado, $84 \%$ das células têm áreas inferiores a $0,5 \mathrm{~km}^{2}$ e $2,3 \%$ possuem áreas superiores a $2 \mathrm{~km}^{2}$.

A área de estudo do carste se insere dentro dos metacalcários dolomíticos, que se distribuem em duas faixas, sendo uma a sul, de Campo Magro a Bocaiúva do Sul, com larguras entre dois e cinco quilômetros; e outra a norte, paralela à primeira, com largura no sentido nordeste de três a sete quilômetros, passando por Itaperuçu, Rio Branco do Sul e Bocaiúva do Sul.

Entre essas duas faixas, existem diferenças geomorfológicas. Segundo COMEC (2002, p 9-6/32): "O dolomito da faixa norte apresenta-se geralmente quase aflorante, possui uma cobertura de solo residual pouco espessa e exibe um relevo ondulado. As rochas carbonáticas da faixa sul são freqüentemente cobertas por sedimentos argilo-arenosos, que atingem ocasionalmente $50 \mathrm{~m}$ de profundidade, e caracterizam-se geralmente por um relevo plano."

Esse estudo desenvolvido por COMEC (2002) definiu basicamente, para as rochas da Formação Capiru, duas zonas, denominadas de Zona de Influência Direta e Zona de Influência Indireta. (mapa 2).

A Zona de Influência Direta é definida como: "situada diretamente sobre os metacalcários dolomíticos, caracterizada, portanto, por um lado, por maior vulnerabilidade ambiental e geotécnica, e por outro lado, por estar diretamente relacionada às características de recarga e produção do aqüífero." COMEC (2002, p. 9-6/32).

A Zona de Influência Indireta é definida como: "compreendida pelas áreas de quartzitos e filitos intercalados por metacalcários dolomíticos e pelas áreas das 
rochas do entorno, cuja drenagem corre para os calcários. Com exceções insignificantes, a zona de influência indireta é constituída por filitos e quartzitos." COMEC (2002, p. 9-6/32).

MAPA 2 - ALMIRANTE TAMANDARÉ: ZONEAMENTO DO CARSTE

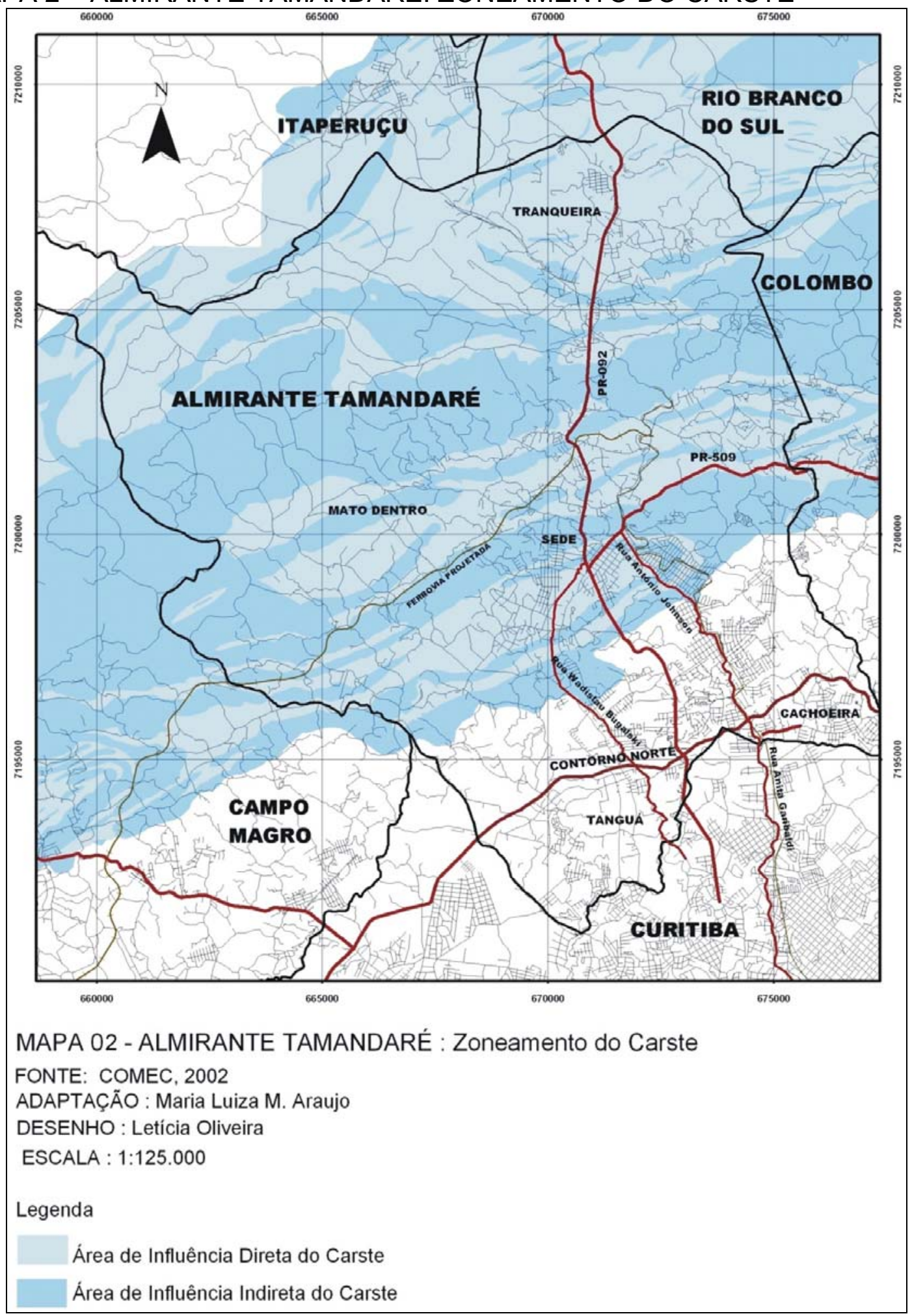

A área estudada pela COMEC (2002) corresponde a $1046 \mathrm{~km}^{2}$, onde se destacam: i) a zona de influência direta, composta por calcários dolomíticos, 
aluviões e diques com $217 \mathrm{~km}^{2}$; ii) a zona de influência indireta, composta por filitos e quartzitos com $262 \mathrm{~km}^{2}$; e iii) as zonas sem influência do aquífero, composta por migmatitos, Formação Setuva e Formação Guabirotuba com 567 $\mathrm{km}^{2}$.

Conforme COMEC (2002), os poços de abastecimento de água subterrânea em operação pela SANEPAR na área estudada correspondem a um total de 37 poços, localizados nos municípios de Almirante Tamandaré, Bocaiúva do Sul, Campo Largo, Campo Magro, Colombo, Itaperuçu e Rio Branco do Sul.

Uma informação preponderante para a análise do uso e ocupação do solo diz respeito ao fato de que todas as células do carste podem agir como pontos de recarga e, por conseguinte, são capazes de absorver qualquer elemento poluidor que seja transportado pela água das chuvas. COMEC (2002, p. 9-13/32).

Nesse sentido, além da ocupação controlada nas áreas de influência direta do carste, deverão ser controlados a drenagem superficial e o esgotamento sanitário das áreas de influência indireta.

A ocupação urbana em áreas cársticas normalmente ocorre sobre as áreas de influência direta, devido às suas características de topografia favorável, como as planícies cársticas. Estas áreas encobrem a complexidade da dinâmica do carste, suas estruturas subterrâneas (cavidades, cavernas) e zonas de extrema sensibilidade, e que não devem ser ocupadas pelos riscos de afundamento dos terrenos.

São considerados locais mais frágeis as zonas e pontos de recarga do aqüífero, chamadas de estruturas de recarga, em especial os poljés, as planícies aluvionares e as dolinas. (COMEC, 2002).

Em Almirante Tamandaré contabilizou-se o total de áreas que integram a região cárstica que é de $147,78 \mathrm{~km}^{2}$, o que corresponde a $77,44 \%$ da área total do município.

As áreas de influência direta correspondem a $71,25 \mathrm{~km}^{2}(37,29 \%$ da área do município) e as áreas de influência indireta correspondem a $76,73 \mathrm{~km}^{2},(40,15 \%$ da área do município).

Percebe-se com base nos dados expostos a complexidade que envolve o espaço urbano de Almirante Tamandaré, o qual possui uma parcela considerável de sua ocupação urbana sobre área de alta fragilidade.

\section{ACIDENTES GEOLÓGICOS EM ÁREAS CÁRSTICAS}

Nas áreas de carste, o crescimento urbano em geral surge a partir do desenvolvimento da principal atividade econômica, inerente ao seu contexto geológico, que é a mineração de calcário, e a tendência natural de ocupação é ao longo das áreas planas e eixos viários.

Em Almirante Tamandaré a ocupação urbana às margens da PR-092, com diversas indústrias de extração e beneficiamento mineral, vem se consolidando até a localidade de Tranqueira, que é definida como uma importante fonte de abastecimento futuro dos mananciais subterrâneos, que deve ser protegida pela sua fragilidade ambiental.

A relação entre a mineração e o crescimento urbano gera um processo de industrialização, que ocasiona um aumento na demanda pelo uso da água, tanto para o abastecimento urbano, quanto para as atividades econômicas. Esse 
processo gera como conseqüência uma intensificação na extração da água subterrânea.

As diversas atividades desenvolvidas, quando realizadas de maneira desordenada, sem os critérios técnicos adequados, podem contribuir para a ocorrência de processos indutores de acidentes geológicos, que se apresentam na forma de afundamentos e/ou abatimentos. (OLIVEIRA, 1997).

Conforme Oliveira (1997), a mineração de calcário, que constitui a matériaprima para as indústrias produtoras de cimento, cal e corretivo do solo, promove a degradação ambiental, além de poluição visual, sonora e do ar. As vibrações produzidas pelas explosões de rochas podem ocasionar danos e avarias às estruturas e fundações em edificações situadas em áreas vizinhas. Na região de carste as ondas vibratórias podem desestabilizar as cavidades subterrâneas, potencializando o risco de abatimentos de terrenos.

A extração de rochas calcárias é a principal atividade de mineração do Estado do Paraná, considerando-se a quantidade e o valor de produção, sendo a Região Metropolitana de Curitiba a principal fornecedora desse bem mineral, que é especialmente presente nos municípios de Almirante Tamandaré, Colombo e Rio Branco do Sul. (OLIVEIRA, 1997).

Os municípios que integram a região do carste foram responsáveis por $9,53 \%$ da produção industrial da RMC, com destaque para as indústrias extrativas e de transformação de minerais não metálicos. (COMEC, 2002).

Os impactos gerados pela mineração, ao que parece, ainda são pouco estudados, sendo que um ponto importante a ser aprofundado, se refere à pesquisa dos reflexos provocados pelos resíduos resultantes da exploração mineral na saúde da população.

O tipo de atividade realizada na região, que decorre das fontes minerais existentes, "representa uma atividade de considerável impacto ambiental, seja pela extração de minérios em áreas de captação do Karst, com deslocamentos de solo e subsolo, seja pela quantidade de resíduos industriais (...), constituindo-se na quinta maior indústria poluidora" (COMEC, 2002, p. 18-7/28). As indústrias que ocupam os primeiros lugares com relação à poluição são as indústrias químicas, de fumo, madeira e papel e celulose.

Há um outro risco de grande relevância, que está associado à exploração do aqüífero em áreas já urbanizadas, pois o rebaixamento do nível da água é o maior responsável pela ocorrência dos afundamentos cársticos, compostos de subsidências $^{6}$ e colapsos de solo $^{7}$, que surgem a partir do esvaziamento das cavidades existentes. Os períodos de estiagem são os mais perigosos por corresponderem a uma maior necessidade de bombeamento de água. (OLIVEIRA, 1997).

A ocupação urbana desordenada, a exploração sem critério dos recursos naturais do carste, a mineração de calcário e a extração de águas subterrâneas formam o conjunto de fatores que causam os acidentes geológicos em terrenos cársticos.

\footnotetext{
${ }^{6}$ Subsidências são movimentos lentos, onde há adensamento do solo, que ocasionam recalques em fundações, trincas e rachaduras nas construções.

7 Colapsos de solo são movimentos bruscos que podem ocorrer mesmo sem sinais prévios denunciadores, que ocasionam desabamentos e afundamentos de terrenos de alto risco.
} 
A exploração do carste para abastecimento urbano é nova na RMC, onde os primeiros poços foram executados há cerca de 15 anos, conforme COMEC (2002), sem conhecimento da fragilidade e do comportamento do aquífero.

A problemática de uso e ocupação do solo em áreas cársticas, segundo COMEC (2002), surgiu na sede de Colombo e na localidade rural de Fervida, após a perfuração de poços para exploração de água.

No início esta exploração acarretou na redução de oferta de água superficial, provocando o esgotamento de várias nascentes e nas situações de estiagem foi verificada a perda da umidade geral do solo. Ocorreram também, subsidências e recalques que causaram rachaduras em edificações, e a formação de crateras próximas aos poços de exploração.

Entre os acidentes em áreas urbanas no Brasil, ligados à evolução de carste coberto $^{8}$, Oliveira (1997) destaca os ocorridos em Cajamar (SP) e Almirante Tamandaré.

O caso de Almirante Tamandaré está intimamente ligado à exploração de água subterrânea, que teve início em 1992, com a operação da Companhia de Saneamento do Paraná - SANEPAR, que visava o abastecimento de água da Região Metropolitana de Curitiba.

A demanda imposta ao aqüífero, através de nove poços instalados na cidade, provocou o rebaixamento do lençol superficial, propiciando uma rápida modificação da saturação da camada superficial do terreno. Os resultados foram os abaixamentos dos terrenos com amplitudes de até $4,0 \mathrm{~cm}$, com o surgimento de avarias em diversos imóveis, todos com fundações rasas e de baixo índice de rigidez, o que ocasionou a necessidade de indenização dos proprietários.

No município de Almirante Tamandaré, existem cinco poços na sede municipal e cinco na localidade de Tranqueira. Esses locais possuem alto potencial para abastecimento de água, porém a ocupação urbana existente pode comprometer a qualidade hídrica do aqüífero. Isso significa que essas captações devem ser desativadas gradualmente, segundo COMEC (2002), evitando também que os acidentes geológicos sejam potencializados.

As áreas de maior restrição do carste, a partir do estudo da COMEC (2002), passaram a ser conhecidas em detalhe, destacando-se a localização e dimensão dos poljés, aluviões e dolinas, além das células com potencial hidrogeológico sobre áreas de influência direta em Almirante Tamandaré.

$\mathrm{Na}$ sede do município essas células correspondem a $0,719 \mathrm{~km}^{2}$; na localidade denominada Haras $\left(0,201 \mathrm{~km}^{2}\right)$; São Miguel $\left(0,656 \mathrm{~km}^{2}\right)$; Marmeleiro $\left(0,506 \mathrm{~km}^{2}\right)$; Morro Azul $\left(0,603 \mathrm{~km}^{2}\right)$; Campo Grande $\left(0,853 \mathrm{~km}^{2}\right)$; Tranqueira $\left(1,492 \mathrm{~km}^{2}\right)$; Cercadinho $\left(0,541 \mathrm{~km}^{2}\right)$ e Boichininga $\left(0,261 \mathrm{~km}^{2}\right)$.

A ocorrência de campos de dolinas ou sumidouros em Almirante Tamandaré foi verificada na localidade chamada Mato Dentro, situada a $4 \mathrm{~km} \mathrm{NW}$ da sede municipal.

Neste município, assim como em outras regiões cársticas, os afundamentos que ocorreram nas porções frágeis refletem uma falta de planejamento e de conhecimento das características geológicas, além de um indevido processo de ocupação e expansão urbana. Acrescido a esses fatores está a exploração sem

\footnotetext{
${ }^{8}$ Carste coberto refere-se ao calcário em dissolução capeado por solos ou sedimentos. OLIVEIRA
} $(1997$, p.3) 
critérios dos recursos naturais, notadamente a extração de água subterrânea e a mineração de calcário. (OLIVEIRA, 1997).

Nas fotografia 1, 2 e 3 destacam-se exemplos de colapsos naturais de solo em áreas cársticas provocados por vibrações de tráfego pesado e nas FOTOGRAFIAS 4 e 5 colapsos induzidos pela extração de água subterrânea em células do carste com ocupação urbana. (mapa 3).

\section{FOTOGRAFIAS 1, 2 E 3 - COLAPSO NATURAL EM ÁREA CÁRSTICA}

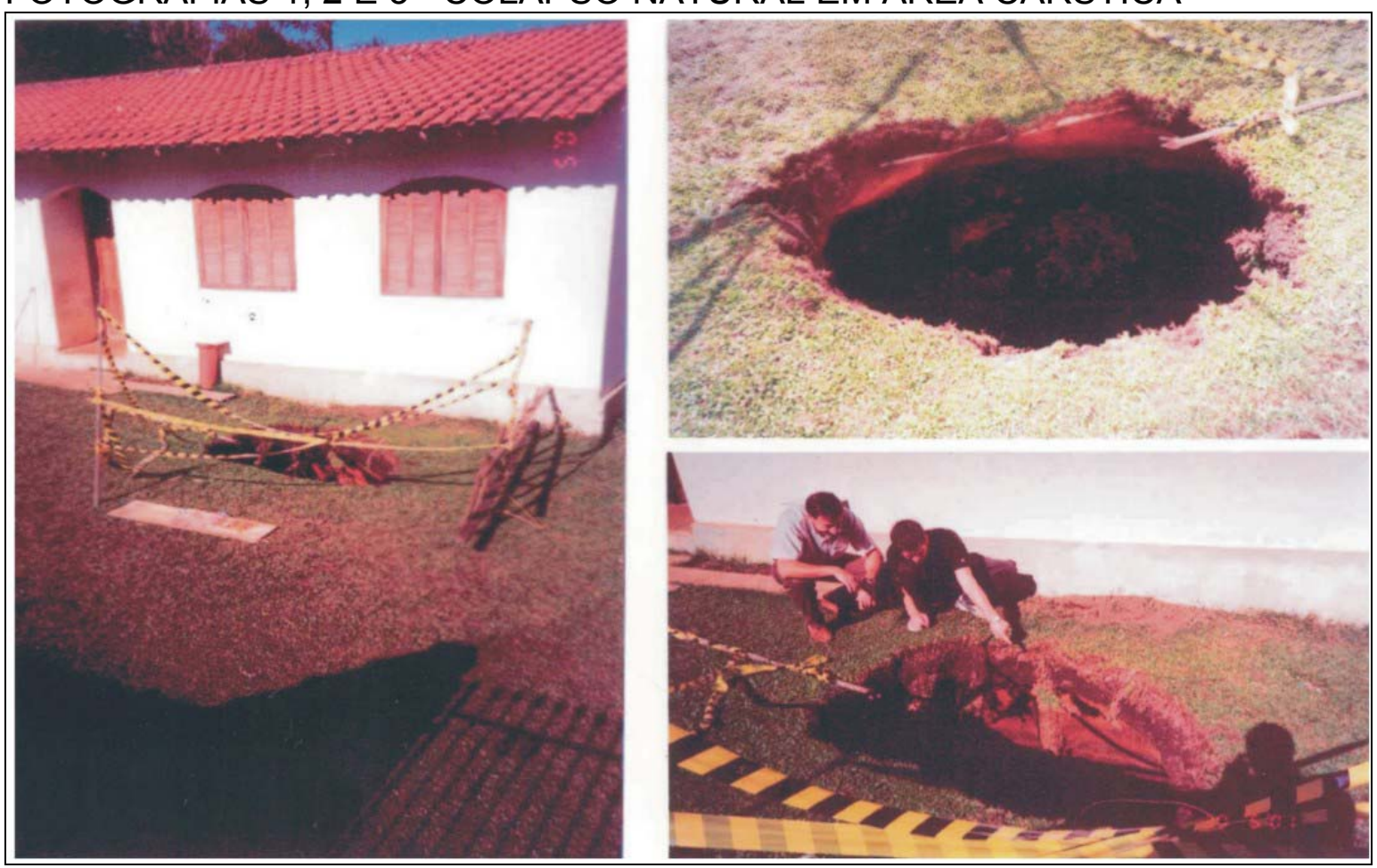

FONTE: MINEROPAR, 2001.

FOTOGRAFIAS 4 E 5 - COLAPSO INDUZIDO PELA EXTRAÇÃO DE ÁGUA SUBTERRÂNEA

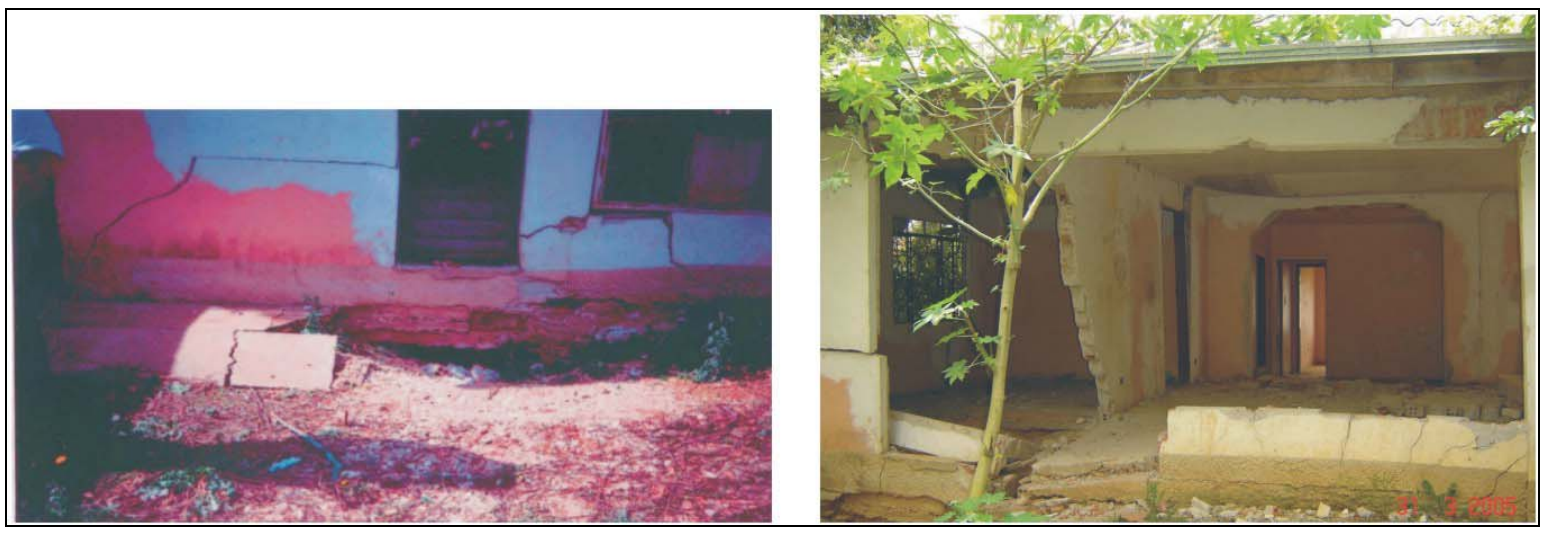

FONTE: MINEROPAR, 2001.

MAPA 03 - ALMAIRANTE TAMANDARÉ: LOCALIZAÇÃO DAS FOTOGRAFIAS 


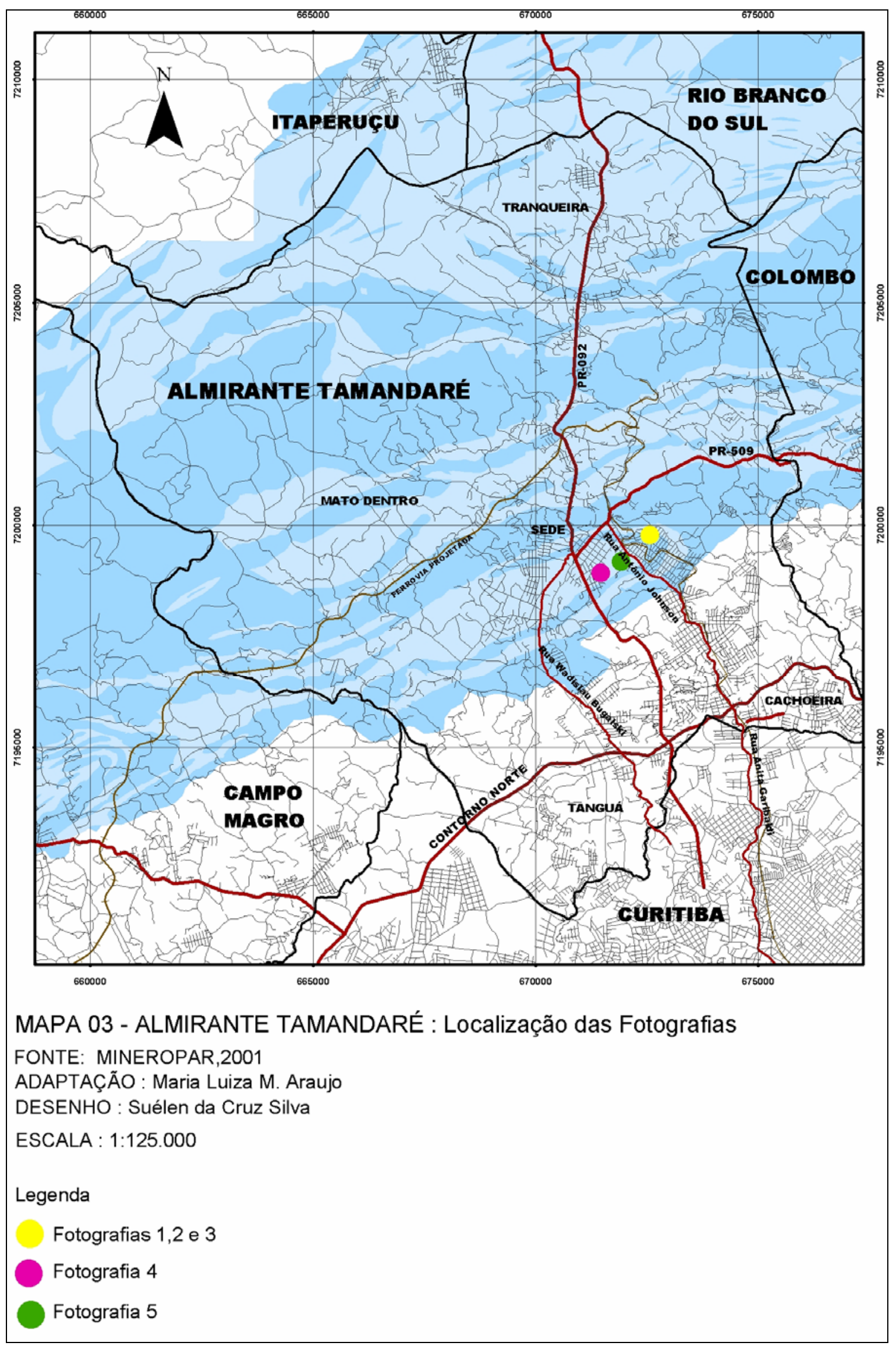




\section{CONSIDERAÇÕES FINAIS}

Em síntese a influência do aqüífero carste no espaço urbano do município de Almirante Tamandaré refere-se à baixa capacidade do meio físico de suportar maiores densidades, à proteção da qualidade da água dos mananciais e, em especial, quanto à fragilidade das áreas de influência direta do carste.

São considerados como possibilidades concretas de intervenção os novos instrumentos previstos pelo Estatuto da Cidade, os quais apesar de não eliminarem as disparidades sociais, são instrumentos importantes para orientar uma ocupação do espaço socialmente justa e mais adequada do ponto de vista ambiental.

E ainda ressalta-se que, a partir da identificação dos limites de suporte do meio físico às atividades antrópicas que visam garantir a sustentabilidade, devese "buscar um ponto de equilíbrio que não comprometa a qualidade dos mananciais e a preservação da biodiversidade, das áreas verdes e dos recursos naturais." (COMEC, 2002, p. 20-5/12).

A partir dessas considerações ficam evidenciados os principais problemas a serem tratados e que demonstram a complexidade desse espaço, o que remete a uma reflexão sobre o futuro da cidade.

Nesse contexto, em que as questões urbanas e ambientais se agravam paulatinamente, as possibilidades de intervenção só serão eficazes se forem tomadas medidas visando à solução das questões sociais, com a efetiva participação da sociedade civil no processo, sendo que a sustentabilidade urbana está intimamente dependente dessas soluções, que devem prever a integração entre o espaço natural e o espaço social.

O uso e a ocupação no contexto urbano cárstico devem considerar as características físicas, geológicas e hidrogeológicas do ambiente, pois além do risco de acidentes geológicos há o risco de contaminação dos aqüíferos subterrâneos.

Com base nas considerações acima, conclui-se que a ocupação e o uso impróprios de áreas geológicamente sensíveis, produz conseqüências que impactam o meio ambiente e a qualidade de vida, o que pode ser considerado como um fator preponderante para a insustentabilidade, tanto do meio urbano, quanto do meio rural.

\section{REFERÊNCIAS}

BIGARELLA, J. J.; BECKER, R. D.; SANTOS, G. F. Estrutura e origem das paisagens tropicais e subtropicais. Florianópolis: UFSC, v. 1, 1994.

CHRISTOFOLETTI, A. Geomorfologia. 2a ed. São Paulo: Edgard Blücher, 1980. COORDENAÇÃO DA REGIÃO METROPOLITANA DE CURITIBA. Plano de zoneamento do uso e ocupação do solo da região do karst da Região Metropolitana de Curitiba. Paraná, 2002.

LIMA, M. C. Fragilidade ambiental da bacia do rio Pacatuba. Curitiba, 2004. 89 f. Monografia (Especialização em Análise Ambiental) - Departamento de Geografia, Setor de Ciências da Terra, Universidade Federal do Paraná. 
LISBOA, A. A. Proposta de metodologia para avaliação hidrogeológica do aqǘfero cárstico, compartimento de São Miguel. Curitiba, 1997. $137 \mathrm{f}$. Dissertação Mestrado em Geologia - Setor de Tecnologia, Universidade Federal do Paraná.

LISBOA, A. A.; BONACIM, E. A. Sistema aqüífero cárstico: reservatório elevado da Região Metropolitana de Curitiba. Revista SANARE. n 4. Curitiba, 1995.

OLIVEIRA, L. M. A gestão de riscos geológicos urbanos em áreas de carste. Curitiba: MINEROPAR, 1997.

PILÓ, L. B. Geomorfología cárstica. In: Revista Brasileira de Geomorfologia. Minas Gerais, v. 1, n. 1, p. 88-102, 2000.

TEIXEIRA, W.; TOLEDO, M. C. M.; FAIRCHILD, T. M.; TAIOLI, F. Decifrando a terra. São Paulo: Oficina de Textos, 2001. 